\title{
THEATRE ACTIVITY IN THE SOUTHERN URALS AT THE INITIAL PERIOD OF THE THAW
}

(C) 2017

\author{
Morozova Irina Pavlovna, teacher of history and social theory \\ Lyceum №2 (Orenburg, Russian Federation)
}

Abstract. The paper deals with the problems of theatre activity development in the southern Urals at the initial period of the thaw. The research objective is to define what changes happened in the theatre activity in the Southern Urals after Stalin's repressions in 1953-1964. For the research the author used periodicals, archival documents, books about the theater. The research has shown that after Stalin's personality cult exposure there were big theater changes in the southern Urals. People became more interested in the theatre. It was in Bashkiria where the theater developed greatly. The paper examines the creative activity of theatres in the southern Urals, Orenburg Region and Bashkortostan, reveals specific features and problems in the functioning of the studied institutions in the era of the thaw, studies repertoire policy of theaters. The repertoire updated and new theaters opened. Actors and directors found new forms of art self-expression. Drama art stops being the weapon of the political propaganda. The author has no opportunity to carry out a comparative analysis of this research with other researches as the subject has not been investigated by anybody yet.

Keywords: theatre; theatre arts; theatre activities; theatrical repertoire; touring theatres; attendance at theatrical events; art; theatre companies in southern Urals; acting; artistic expression; theatre; drama theatre; playwright; tour posters; Director's vision; staging; regional theater; creative way.

УДК 94

Статья поступила в редакцию 25.08.2017

\section{ВНЕШНЯЯ ПОЛИТИКА США В ПОСЛЕДНЕЙ ЧЕТВЕРТИ ХІХ - НАЧАЛА ХХ ВЕКА И СОЦИАЛ-ДАРВИНИСТСКАЯ ИДЕОЛОГИЯ}

(C) 2017

\author{
Мухатаев Павел Николаевич, учитель истории и обществознания \\ Средняя общеобразовательная школа № 7 г.о. Самара (2. Самара, Российская Федераџия)
}

Аннотация. В данной статье представлен краткий обзор историографии внешней политики Соединенных Штатов Америки, а также анализ причин возникновения экспансионистской парадигмы США конца XIX начала XX века. Обширная советская историография дает представление об экономическом аспекте событий в США в указанный период, у зарубежных авторов более многомерное представление о происходивших событиях. А. Шлезингер, например, заявлял о второстепенности экономических причин активной внешней политики Соединенных Штатов Америки, указывая политические причины первостепенными. Социалдарвинизм как явление, формировавшее внешнюю политику, рассматривается историками лишь косвенно. В российско-советской историографии социал-дарвинизм обозначается как некий фактор, опосредованно влиявший на политику. Американская историография более цельно рассматривает предмет нашего исследования, но в контексте анализа либеральной идеологии. Автор статьи указывает на роль идеологических причин принятия руководством Соединенных Штатов Америки внешнеполитических решений. В статье делается попытка выяснить, существовала ли связь активной внешней политики с социал-дарвинистским дискурсом, который прослеживается и у сторонников данного курса, и у ее противников в политических, экономических и интеллектуальных элитах американского общества на рубеже веков.

Ключевые слова: социал-дарвинизм; внешняя политика США конца XIX - начала XX века; Г. Спенсер; А. Беверидж; К. Шурц; Ч. Конант; А. Мэхен; Ф. Тернер; Э. Карнеги; Т. Рузвельт; англосаксонская раса; Г. Зинн; А. Шлезингер; Б.Д. Козенко; А.П. Раскин; Г.И. Мусихин; А.Б. Гофман; экспансионизм.

Внешняя политика Соединенных Штатов Америки в конце XIX - начале XX века характеризуется многими историками как «экспансионистская».

После Гражданской войны и Реконструкции в США бурно развивалась экономика, для которой внутренний рынок Соединенных Штатов становился недостаточным для реализации своих амбиций и возможностей. Эти процессы очень хорошо описаны советскими историками, например, в четырехтомнике Истории США [1]. Преодоление связанных с этим проблем, например перепроизводства и экономической депрессии, было связано с активной внешней политикой США.

В последней четверти XIX века правительство Соединенных Штатов Америки стало смотреть за пределы собственных территорий. В 1880-90-е годы XIX века руководство страны активно наращивало военно-морской потенциал. К 1893 году морской флот Соединенных Штатов по своим возможностям вышел на пятое место в мире, и этот рост продолжался с еще большей энергией в начале XX века при президенте Т. Рузвельте [1, с. 149; 2, с. 258-278]. Наращивание военной силы не прошло бесследно. В 90-е годы XIX века к Соединенным Штатам Америки были присоединены Гавайские острова, которые, по мнению историков, укрепляли позиции США в Тихом океане и способствовали продвижению американских интересов на Восток Азии [3]. В 1898 году произошла война с Испанией, владеющей о. Куба и рядом островов в Тихом океане. Причем война началась с трагедии на броненосце «Мэн», которая, согласно исследованиям, была не до конца расследована и являлась предлогом для начала войны $[4$, c. 333$]$. 
В американской историографии существует совсем противоположная интерпретация событий, произошедших во второй половине XIX века. Артур М. Шлезингер выразил следующую точку зрения: «Империализм никогда не был широко распространенным массовым движением [в США]. Были всплески ура-патриотического неистовства, как, например, по поводу потопления «Мэна», но заметное и постоянное требование строительства империи отсутствовало» [5, с. 221]. Хотя историк тут же замечает, что «Соединенные Штаты - экспансионистская страна» [5, с. 187]. Однако экспансионизм Шлезингера в контексте истории США - экспансионизм «внутренний», распространяющийся на территории Запада Северной Америки, тогда как внешнеполитические приобретения XIX века, по мнению ученого, не стали колониями в классическом понимании либо были освобождены от прямого американского влияния.

Экономические связи не могли установиться наиболее прочно, по мысли Шлезингера, из-за бедности регионов, переходивших под протекторат США, и малой популярности товаров, которые предлагали эти страны в самих Штатах. Данное обстоятельство говорит о том, что марксистский базис экономика - не всегда является главным аргументом в принятии политических решений, в том числе и внешнеполитических.

В наши задачи не входит оценивать политику США конца XIX века или оспаривать мнения авторитетных историков. Мы сделаем попытку разобраться в идеологическом дискурсе, который непосредственно связан с тем контекстом, который обозначен нами выше. Доминирующие идеи и представления о справедливом и закономерном устройстве общества, выраженные в определенных терминах и понятиях, формируют дискурсивные практики, которые обосновывают или критикуют официальную политику государства.

В нашем распоряжении достаточное количество источников, которые характеризуют атмосферу дискурса в Соединенных Штатах Америки конца XIX века. Публичные выступления - речи политических деятелей в письменной и устной формах - является интереснейшими источниками, которые отражают и формируют общественную мысль, поэтому мы обратимся к наиболее известным материалам и постараемся их проанализировать, тем более что «...в ядре идеологий содержится кластер неопровержимых и неоспариваемых понятий, которые образуют между собой очевидную идеационную сеть, способную существовать на протяжении длительного времени в относительно неизменном виде. Данная сеть - это неэлеминируемые ключевые понятия, которые представляются должными в актуальной политической повседневности» [6, с. 12-13]. Ключевые понятия социал-дарвинисткой идеологии выражаются такими известными оборотами, как «выживание сильнейших», «естественный отбор», «эволюция», «борьба за существование», которые рассматривают социальное бытие как арену непрерывных конфликтов между индивидами, обществами и т.д., и аналогиями общества с живым организмом. Также, на наш взгляд, в американском обществе того времени очень весомое значение имела расовая теория превосходства англосаксонской расы. Современные ученые классифицируют эти идеи отдельно, выделяя социалдарвинистскую научную школу и расово-антропологическую, но, на наш взгляд, ученые, политики, журналисты, экономисты конца XIX - начала XX века были далеки от современной классификации тех идей, которыми они пользовались в повседневной практике, и эти идеи следует рассматривать в некоем синкретическом единстве [7, с. 164, 148]. Для того чтобы идентифицировать социал-дарвинисткие идеи, нам и необходим дискурсивный анализ общественной мысли в США рубежа XIX-XX веков, который и должен помочь выявить идеологические убеждения, ставшие аксиомой для определенной группы американского общества. Социал-дарвинизм в Соединенных Штатах рубежа XIX-XX веков - это идеи, которые «потерпели победу» и использовались многими авторами как «данность», неоспоримая и не подлежащая полемике. «Вокруг нас много борьбы, - пишет контр-адмирал Альфред Мэхен, - и такие выражения, как «борьба за жизнь», «гонка на выживание», являются настолько знакомыми, что мы не чувствуем их значения, пока не задумываемся об этом» [8, p. 18-19].

Чарлз Артур Конант, видный американский журналист, экономист и политик конца XIX века, в своей статье «Экономическая основа "империализма"» ярко и аргументированно отстаивает активную внешнюю политику США.

По мысли Конанта, в таких промышленно развитых странах, как Соединенные Штаты Америки, накапливается огромный избыток капитала, и для того чтобы экономическая система развитых стран не пострадала от социального взрыва, вызванного перепроизводством, промышленникам необходимы новые рынки сбыта. «...Избыток сбережений в сочетании с сопровождающим его накоплением невостребованных товаров в крупных индустриальных странах является сегодня одной из мировых экономических болезней...»- пишет Ч.А. Конант [9, с. 143].

Следовательно, Соединенные Штаты должны обратить свое внимание за пределы собственных границ. Война или дипломатические успехи на данном пути - это лишь детали. «Нет даже необходимости спорить по поводу того, следует ли «торговле следовать за флагом» или цели торговли могут быть достигнуты в отсутствии престижа политической мощи страны» [9, с. 147].

В данном источнике следует обратить внимание на то, каким понятийным аппаратом пользуется автор. В первой же строке своей статьи Чарлз Конант пишет о «инстинктивном стремлении человеческого рода», в переведенной Э.А Иваняном хрестоматии или, как указано в первоисточнике, «инстинктивном стремлении расы», которое, по словам автора статьи, «обгоняет разум их лидеров» и подталкивают США к экспансионистской внешней политике. Далее хрестоматийный перевод передает в точности характер высказанного в статье, а именно: «...когда поток расовых или национальных стремлений обретает мощь... он способен преодолеть как сомнения своих сторонников, так и протесты и сопротивление... сегодня Соединенные Штаты вступают на путь, предназначенный им как отпрыскам англосаксонской расы...» $[9$, c. $141 ; 10$, p. 326]. Далее Конант пишет, что «это новое движение не является продуктом той или 
иной идеи. Оно является следствием естественного закона экономического развития, а также законом развития рода человеческого» [9, с. 142]. Опираясь на первоисточник, можно перевести более прямолинейно: «это новое движение - не вопрос настроений. Это сущность естественного закона экономического и расового развития» $[10$, р. 326]. Далее Чарлз А. Конант добавляет к данной аргументации то, что, по его мнению, активная внешняя политика соответствует «закону самосохранения» и «выживанию наиболее приспособленных» [9, с. 142; 10, р. 327].

Чарлз Конант являет собой яркий пример социалдарвинисткой риторики в США конца XIX века в классической его форме. В своей аргументации активной внешней политики Конант использует как расовый подход, который, по его мнению, является важной составляющей успеха Соединенных Штатов в покорении новых рынков, так и биологическую редукцию, выраженную в апелляции к «выживанию наиболее приспособленных» и «закону самосохранения».

Принято считать, что только в агрессивную, воинственную политику проникает социал-дарвинистский дискурс. Однако, на наш взгляд, даже апологеты миролюбивой политики, в данном случае внешней, оказались восприимчивы к социал-дарвинистской риторике. Журналист, политик, военный - Карл Шурц знаменит своими статьями, критиковавшими активную внешнюю политику США конца XIX века. В своей статье «Предопределенная судьба» Шурц доказывает, что Соединенные Штаты имеют исключительное по отношению к передовым европейским странам географическое и политическое положение, которое позволяет не сильно отвлекаться на опасность из-за океана, как Тихого, так и Атлантического, и не опасаться соседних государств с севера и юга из-за их недостаточного экономического и политического развития. Эти преимущества, по мысли Карла Шурца, должны использоваться с максимальной выгодой для США мирными методами, тогда как активное вмешательство - аннексия какой-либо территории (Мексики или Гавайских островов) с населением, отличающимся по своим особенностям от американцев, приведет к развалу политических институтов и разложению американского общества [11, p. 737-746; 12, с. 116-128]. Причинами столь радикальных изменений, по мнению Шурца, которые могли бы привести к столь печальным для США последствиям, являются как раз-таки расовые различия, которые определяются формированием климата и условиями жизни.

В дополнение к своим утверждениям К. Шурц добавляет: «...высокая температура препятствует любому устойчивому напряжению... и усилия по стимулированию и организации труда для крупномасштабного производства так или иначе достигаются путем принуждения [имеется в виду народов, живущих в тропиках]... не существует ни одного примера роста сильной англосаксонской демократии в тропических широтах... Индия насчитывает едва ли более одного европейца на 3500 населения и управляется через военные гарнизоны, которые, поскольку состоят из англичан, должны время от времени пополняться из Англии...». Если США придется включить в свой состав другие территории и народы, ко- торые разительно отличаются от американского своими культурными и расовыми различиями, то это может привести к уничтожению политических традиций, которые, по мнению К. Шурца, являются основой американского общества. Причем с помощью демократических процедур, которые отстаивались американским народом.

Пример Карла Шурца показывает амбивалентность расовой аргументации. Если Конант говорит о преимуществах и возможностях англосаксонской расы в отношении внешней политики, то Шурц говорит о ее ограниченности, следовательно и рисках, которые могут привести из-за необдуманной и излишне активной внешней политики США.

Альберт Дж. Беверидж - политик, юрист и историк, яркий оратор. В своем выступлении «Поступь флага» Беверидж призывает политиков и общественность не выбирать своим уделом трусость во внешней политике, как это делают Китай, Индия или Египет, а вести активную внешнюю политику, которая способствует распространению тех ценностей, которые взращиваются в Соединенных Штатах. «...Справедливое правительство получает свои полномочия с согласия управляемых только в том случае, если они способны к самоуправлению. Мы управляем индейцами без их согласия, мы управляем нашими территориями без их согласия, мы управляем нашими детьми без их согласия...» [13, р. 48-49]. Такими оборотами пронизано все выступление, но уже здесь выделяется идея расового превосходства, которое диктует американцам, как более развитой расе, контроль над индейцами. Далее Беверидж приписывает все успехи американской нации чувству принадлежности к англосаксонской расе, которое двигает американцев вперед в экономическом и политическом развитии [13, p. 50-51]. Активная внешняя политика в таком случае будет помогать «...борьбе за рынки и войне за коммерческое существование...» [13, р. 54].

В другом выступлении, которое называется «Звезда Империи», полемизируя с У. Брайаном - кандидатом в президенты от демократической партии - о целях внешней политики, Беверидж от лица республиканцев продолжает обосновывать активную внешнюю политику США, говоря о том, что цивилизованная организация жизни на Филиппинских островах или Кубе возможна лишь при условии управления народами, населяющими данные территории, осуществляемого англосаксами. «...На этих островах должно быть организовано правление закона, которое основывается на гении крови членов администрации» [14, p. 121].

В обоих выступлениях Альберт Бэверидж говорит о превосходстве англосаксов в политическом развитии, тогда как филиппинцы или кубинцы предстают в лучшем случае в роли неразумных детей или, что хуже, нецивилизованных варваров, которым жизненно необходима поддержка американского правительства. Опыт англосаксонской расы должен, по мысли автора, облагородить отставшие в своем развитии расы. С другой стороны, Беверидж не забывает и о конкурентах, с которыми необходимо вести «борьбу за коммерческое существование», что отсылает нас к популярным в то время в США идеям Герберта Спенсера, побывавшего в США в 1883 с лекциями $[15$, с. 110$]$. 
В противовес Ч. Конанту и А. Бевериджу со статьей под названием «Американизм против империализма» выступил сталелитейный магнат Эндрю Карнеги. Позиция Э. Карнеги сходится с идеями Карла Шурца в том, что американцам не стоит впутываться в чрезмерно активную внешнюю политику и прибегать к тем или иным военным альянсам для приобретения новых территорий. Более того, главная угроза для США - это «...опасность войн с другими странами» $[16$, p. 12]. Экономические потери в отсутствии новых рынков сбыта, по мнению Карнеги, будут крошечными, а именно не более чем четыре процента от общего экономического оборота. При этом рост экономики за счет активизации внутренней торговли, по оценкам Карнеги, ежегодно примерно будет равен экспорту и импорту США в совокупности. Альтернативой этому, довольно прагматичному подходу может быть путь марионетки в руках более мощных морских держав, например Великобритании [16, p. 9-10]. «Нет ни одного союза, даже самого невообразимого, который не мог бы быть создан...»пишет Карнеги, и подобная беспринципность должна отталкивать Соединенные Штаты Америки от необдуманных шагов к активизации внешней политики [16, p. 4].

Необычно у Э. Карнеги звучит довольно распространенная мысль о расе и ее значении. «Военные альянсы появляются и исчезают из-за вопросов, которые возникают время от времени. Патриотизм расы - глубже и не может быть нарушен подобными поверхностными обстоятельствами... Две страны являются двумя великими народами в мире [США и Россия] - твердыми, компактными, неприступными, потому что каждая освоила ту территорию, на которой может развиваться ее собственная раса» [16, p.6]. Подобное использование понятия «раса» совершенно отличается от тех интерпретаций, которые были рассмотрены выше. «Раса» на протяжении всей статьи Эндрю Карнеги не возносит англосаксов как передовых людей, распространяющих «свет политических институций», а скорее рассматривает «расы» как культурные образования, нежели биологические различия, отличающие людей. Более того, Карнеги говорит о том, что ни филиппинцы, ни индусы не обладают какими-то врожденными недостатками, которые бы не позволили этим народам организовать в своей стране самоуправление. «...Они будут совершать ошибки, но какой народ их не делает? ...неизбежным результатом будет правительство, которое более подходит им, чем могли бы дать наши солдаты...» [16, p. 13]. Данный пассаж снова отсылает нас к Герберту Спенсеру, который во время своей знаменитой поездки в США в своем интервью говорит о степени случайности республиканских и демократических благ, которые выпали на долю американцев. «Америка получила свою форму правления благодаря счастливой случайности, а не в силу естественного процесса, и ... вам придется вернуться назад, для того чтобы быть потом в состоянии идти вперед...» [17, с. 1388]. К этому естественному процессу получения политического опыта и обращается Карнеги, распространяя его на Кубу, Филиппины и т.д.

Фредерик Тернер - историк, представитель прогрессистской школы американской историографии, разработавший концепцию фронтира как ключевого фактора развития американской цивилизации.

Социал-дарвинисткий дискурс не так активно проник в работы историка Тернера, однако он пользуется некоторыми аналогиями из области биологии в духе Герберта Спенсера. Например, описывая этапы развития США на Запад, он говорит: «...очень похоже на развитие и устойчивый рост нервной системы от первоначально чего-то очень простого и инертного... в этом прогрессе из диких условий есть темы, которые могли бы быть предметом исследования эволюционистов» [18, р. 15]. Размышляя над тем, что движет прогрессом в США, Тернер склоняется к идее, что это ничем и никем не ограниченная конкуренция творческих людей. «Необходимо умножить мотивацию для амбициозных и открыть новые возможности для самых сильных» [18, р. 309].

Фредерик Тернер является примером социал-дарвинистской риторики, но был далек от обоснования и распространения самого социал-дарвинизма. Тернер был автором оригинальной концепции фронтира, сформировавшей историю и ценности американцев, но при этом говорил о внешней политике и экспансионизме. Он использовал понятные для большинства его адресатов социал-дарвинистские концепты о «возможностях для самых сильных» и аналогию развития США на Запад с «развивающейся нервной системой».

Еще одним апологетом наращивания мощи морского флота, активизации внешней политики является Альфред Тэйер Мэхен - известный и довольно влиятельный военный и военно-морской историк. В своей известной работе «Интересы Америки в морской мощи в настоящем и в будущем» Альфред Мэхен говорит о том, что старые взгляды на протекционистскую экономическую политику и вялую внешнюю политику уходят в прошлое. «В сущности, отсутствие активной внешней политики чуждо американскому характеру...» $[8$, p. 4-5]. Франция и Великобритания усиливают свои порты без видимых на то причин, но из-за озабоченности своим будущим, считает Мэхен, и США нельзя уступать в этой конкуренции за территории, которые находятся в сфере своих интересов $[8$, p. 21]. Кроме того, Альфред Мэхен уверен, что международное право не в состоянии защитить интересы государства, уступающего в военной силе, сколь бы ни были неправомерны действия против него со стороны сильного агрессора [8, p. 9]. Отсюда А.Т. Мэхен делает вывод, что необходимо усиление военной мощи военно-морских сил США и увеличение внешнеполитической активности, например, в Карибском бассейне. «Ведь наш мир полон превратностей и остается миром борьбы», - пишет Мэхен. Далее контр-адмирал Мэхен пишет как раз об упомянутой выше распространенности социал-дарвинистского дискурса, который настолько прочно вошел в обиход американцев, что его уже не замечали, но который должен был помочь американцам взглянуть на ситуацию, в данном случае внешнеполитическую, с другой стороны [8, p. 18-19]. США должны были, по мысли Альфреда Тэйера Мэхена, начать активно отстаивать свои экономические и политические интересы при помощи военной силы, которой также необходимо было уделять большее внимание со стороны властей. 
Разбирая контекст, в котором писали экономисты, политики, ученые, стоит отметить, что все-таки США начинают проводить все более активную внешнюю политику. Война с Испанией и последовавшие за этим присоединение Филиппин и протекторат над Кубой, присоединение Гавайских островов подтверждают этот тезис. Влияние социал-дарвинистского дискурса, на наш взгляд, сказывалось на реальной политике США. Данную взаимосвязь можно проследить, например, в воздействии тех авторов, которых мы цитировали выше, на политиков, принимавших решения во внешнеполитическом курсе Соединенных Штатов Америки.

В апреле 1897 года Теодор Рузвельт, будущий 26й президент США, стал заместителем министра военно-морского флота США [19, с. 136-139]. В своем письме Альфреду Мэхену, Рузвельт пишет: «... полностью разделяю Вашу точку зрения [по вопросу о Гавайях], как разделяю, впрочем, вообще Вашу позицию по вопросам внешней политики» [19, с. 137].

Также из письма Т. Рузвельта видно, что у сторонников активной внешней политики были достаточно влиятельные оппоненты, например в лице госсекретаря Дж. Шермана и спикера палаты представителей Конгресса США Т. Рида, которые мешали претворению амбициозных внешнеполитических планов в жизнь [19, с. 138-139]. Однако Рузвельт пишет в письме Мэхену: «... Даже в нынешней ситуации я надеюсь на благоприятное развитие событий. Я убеждал министра, а через него и президента, что нам следует действовать сейчас без промедления [По Гавайскому вопросу]...». В письме Рузвельт большее внимание уделяет геополитике, нежели экономическим интересам. Панамский канал, например, необходим Соединенным Штатам в первую очередь для решения военных задач [19, с. 139].

Ранее, выступая в одном из военных колледжей США по поводу нерешительности правительства в вопросе Гавайских островов, Рузвельт произнес следующее: «Все великие господствующие расы сражались. ...Никакой триумф мира не может сравниться с триумфом войны» [Цит. по: 4, с. 329]. Данный отрывок из выступления Теодора Рузвельта подтверждает не только наличие идейной преемственности от Мэхена к Рузвельту, но и наличие социал-дарвинистской риторики, которая использовалась в высших политических кругах Соединенных Штатов Америки. Вот другая яркая цитата Т. Рузвельта, наполненная решимостью призвать американцев к борьбе и конкуренции с другими народами «за лучшее место под солнцем»: «Если мы испугаемся суровых столкновений, в которых можно победить лишь ценой многих жизней и не боясь потерять все, что дорого человеку, тогда более смелые и сильные народы обойдут нас и завоюют господство над миром» [Цит. по: 5 , с. 210].

В заключение данного краткого обзора внешней политики и дискурсивных практик среди представителей политической, экономической и интеллектуальной элиты США конца XIX - начала XX века хотелось бы отметить, что социал-дарвинизм играл заметную роль в выборе аргументации принятия решений. Конечно, у экспансионистской политики бы- ли заметные критики, которые осуждали экстраполяцию идей борьбы за существование и естественного отбора на общество. Однако биологический редукционизм и расовые теории настолько серьезно вошли в повседневный оборот людей разных социальных страт, что приходилось формулировать ответы на злободневные вопросы при помощи понятий, которые были продуктом социал-дарвинистских идей.

\section{СПИСОК ЛИТЕРАТУРЫ:}

1. История США. Т. 2 / под ред. Г.Н. Севостьянова. М.: Наука, 1985. 599 с.

2. Раскин А.П. Развитие морской мощи США (1901-1909 гг.) Американский ежегодник. М.: Наука, 1974. $344 \mathrm{c}$.

3. Козенко Б.Д., Севастьянов Г.Н. История США. Самара. 1994. 479 с.

4. Зинн Г. Американская империя. С 1492 года до наших дней. М.: Алгоритм, 2014. 752 с.

5. Шлезингер А.Циклы американской истории. М.: Прогресс, 1992. 688 с.

6. Мусихин Г.И. Очерки теории идеологии / Нац. исслед. ун-т «Высшая школа экономики». М.: Изд. дом Высшей школы экономики, 2013. 288 с.

7. Гофман А.Б. Семь лекций по истории социологии: учебное пособие. М.: КДУ, 2008. 240 с.

8. Mahan A.T. The Interest of America in Sea Power present and future. Boston: little, brown, and company. 1917. $314 \mathrm{p}$.

9. Конант Ч.А. Экономическая основа «империализма». История США. Хрестоматия: пособие для вузов / сост. Э.А. Иванян. М.: Дрофа, 2007. 399 с.

10. Conant Charles A. The Economic Basis of «Imperialism». The North American Review. Vol. 167, № 502 (Sep., 1898). 384 p.

11. Schurz Carl. Manifest Destiny. Harper's New Monthly Magazine. Vol. 87, Iss. 521 (October, 1893). $810 \mathrm{p}$.

12. Шурц Карл. Предопределенная судьба. История США. Хрестоматия: пособие для вузов / сост. Э.А. Иванян. М.: Дрофа, 2007. 399 с.

13. Beveridge J.A. The march of the flag // Meaning of the times and other speeches. Indianapolis. The bobs Merrill company publishers. 1908.

14. Beveridge J.A. The Star of Empire // Meaning of the times and other speeches. Indianapolis. The bobs Merrill company publishers. 1908.

15. Согрин В.В. Идеология в американской истории: от отцов-основателей до конца XX века. М.: Наука, 1995. 238 с.

16. Carnegie Andrew. Americanism versus Imperialism. The North American Review. Vol. 0168, Iss. 506 (January 1899). 128 p.

17. Спенсер Г. Опыты научные, политические и философские / Пер. с англ.; под ред. Н.А. Рубакина. Мн.: Современ. литератор, 1999. 1408 с.

18. Turner Frederick Jackson. The Frontier in American History. New York. Henry Holt and Company. 1920. $375 \mathrm{p}$.

19. Рузвельт Т. Препятствия к немедленной экспансии. История США. Хрестоматия: пособие для вузов / сост. Э.А. Иванян. М.: Дрофа, 2007. 399 с. 


\title{
AMERICAN FOREIGN POLICY AT THE END OF THE XIX - EARLY XX CENTURIES AND SOCIAL DARWINIST IDEOLOGY
}

(C) 2017

Mukhataev Pavel Nicolaevich, teacher of history and social theory Secondary School №7 of Samara Urban Okrug (Samara, Russian Federation)

\begin{abstract}
This paper presents a historiographical review of American foreign policy, as well as analysis of the causes of the emergence of American expansionist paradigm in the late XIX - early XX centuries. Soviet historians give us an idea about the economic aspect of events in the U.S. during the specified period. However, foreign scientists have multidimensional view on the events. A. Schlesinger as one of the most popular authors insisted on the secondary importance of economic reasons for an active foreign policy of the United States, indicating that political reasons were of paramount importance. Social Darwinism, as a phenomenon that could shape foreign policy is considered by historians indirectly. In the Russian-Soviet historiography Social Darwinism is denoted as a factor that influences policy indirectly. American historiography considers the subject of our study more wholly, but in the context of the analysis of the liberal ideology. The author points to the role of ideological reasons for the American administration's foreign policy decision-making. The paper is an attempt to find out whether there was a connection between foreign policy and the Social-Darwinist discourse, which can be traced in political, economic and intellectual elites of American society at the turn of the century.

Keywords: Social-Darwinism; foreign policy of United States of America in late XIX - early XX centuries; G. Spenser; A. Beverige; A. Carnegie; C. Schurz; Ch. Conant; A. Mahan; F. Turner; T. Roosevelt; Anglo-Saxon race; H. Zinn; A. Schlezinger; B. Kozenko; A. Raskin; G. Musikhin; A. Gofman; expansionism.
\end{abstract}

УДК 94(595)

Статья поступила в редакцию 25.09.2017

\section{КОЛОНИАЛЬНЫЕ ИМПЕРИИ ПОСЛЕ 1945 ГОДА: ВЗГЛЯД ИЗ США}

(C) 2017

Буранок Сергей Олегович, доктор исторических наук, профессор кафедры всеобщей истории, права и методики обучения

Самарский государственный соџиально-педагогический университет (г. Самара, Российская Федераџия)

Аннотация. Исследования колониальной проблематики в условиях холодной войны невозможны без привлечения прессы участников данных процессов. Изучение прессы США даст возможность более глубоко и конкретно осветить американские представления о практических подходах в международных отношениях в условиях трансформации миропорядка после Второй мировой войны. Анализ прессы показал, что в течение 1945 г. в американском общественном дискурсе происходила смена приоритетных подходов: рузвельтовский план ликвидации колониальных империй постепенно заменялся планами сохранения и использования колониальных империй и их опыта для решения новых задач внешней политики США.

Сразу после завершения Второй мировой войны пресса США начинает процесс пересмотра своего отношения к колониальной теме. СМИ США явно отходят от позиций критицизма и переходят к более глубокому и всестороннему анализу как самой системы в целом, так и британского опыта управления колониями, открыто признавая, что в этом вопросе исторические связи, опыт решения конфликтов и управления местными элитами может оказаться более полезным, чем верность абстрактным принципам. В конце 1945-1946 гг. наблюдаются тенденции в прессе США по изменению с позиции заинтересованного наблюдателя на активного участника колониальной проблемы.

Ключевые слова: колониализм; колонии; пресса США; Британская империя; национальные движения в колониях; международные отношения; общественное мнение; холодная война; формирование биполярной системы; американские журналисты; колониальные империи; колониальная политика; национальный вопрос.

Вопросы о перспективах колониальной системы, о переходе в эпоху постколониализма, о возможности применения опыта колониальных империй были одними из наиболее популярных и весьма дискуссионных в американском обществе на протяжении новейшей истории $[1$, р. $10-15 ; 2$, р. $281 ; 3$, р. 1-9; 4, p. $280 ; 5$, p. 11]. Особенно он актуализировался в периоды после Великой войны (1918-1922) [5, р. 12] и на завершающем этапе Второй мировой войны (19441945 гг.) [6, с. 9; 7, с. 116]. Изучение периодической печати США позволит определить более широкий набор моделей решения колониального вопроса, чем анализ только мнения экспертного сообщества и дипломатического корпуса, а главное, даст возможность более глубоко и конкретно осветить американские представления о практических подходах в международных отношениях в условиях трансформации миропорядка после Второй мировой войны.

В период 1944-1945 гг. большинство наиболее авторитетных и читаемых в США журналистов сконцентрировались на европейской политике, которая представлялась и в Белом доме, и в госдепартаменте, и в СМИ краеугольным камнем американской внешней политики. Поэтому как взгляды на колониальную систему, так и модели решения колониального вопроса формировались в США, с одной стороны, под явным влиянием европейского фактора международных отношений: Липпман, Линдли, Уэллс, 